\title{
Creating Cosmopolitan Identities in Transnational Spaces to Advance Gender Equality
}

\author{
Leva Rouhani
}

\section{Introduction}

The unprecedented rise of international development volunteering (IDV) over the past few decades has corresponded with the rise in research around the impact of IDVs making a distinctive contribution to the broader landscape of development work and the implications of understanding IDVs as transnational actors. Central to this analysis is understanding the distinctive role the relationships and partnerships between IDVs and receiving organizations play in creating transnational spaces where dialogue and the diffusion of norms around gender equality programming has created new cosmopolitan identities.

This paper will analyze how IDVs use transnational spaces to build relational networks among partner organizations that support gender equality outcomes. Specifically, this paper will explore how cosmopolitan identities of partner organizations are shaped by virtue of transnational interactions and how global citizenship values are fostered through transnational spaces, mutual learning and reciprocal knowledge sharing. While much of the literature on IDVs focuses on capacity building (Machin 2008), the role of IDVs in bringing new forms of expertise, and the cosmopolitan values experienced by IDVs, the findings from this research emphasize the agency of partner organizations in creating reciprocity and mutual learning. This paper examines transnationalism, reciprocity, and mutual learning from the perspective of partner organizations and the shift in the dynamics that govern transnational spaces where IDVs and partner organizations interact. As the findings in this study reveal, when it comes to gender equality programming, partner organizations play a central role in demonstrating cosmopolitanism and in advancing transnational feminist priorities. Moreover, this paper shows that the flow of knowledge and information sharing is multi-directional and not unidirectional (not limited to North-to-South knowledge sharing), and therefore the lens of cosmopolitanism in transnational spaces is important for understanding how change happens.

\section{Literature Review}

International development volunteering is recognized for the benefits accrued to the international volunteers who are able to enhance their learning, to contribute to greater global awareness, and to promote global citizenship (Chapman 2018). Part 
of the growing desire to engage in international development volunteering derives from the belief that cross-cultural experiences promote cosmopolitan values and engaged global citizens. However, global citizenship identity is not exclusive to the experiences of sojourners. As I argue in this paper, cosmopolitan identities are shaped by IDV interventions and experienced by both volunteers and partners. This section will define key concepts such as global citizenship and cosmopolitanism, before outlining the literature around the role of IDVs in fostering cosmopolitan identities and highlight the gaps in the literature that this paper will fill.

\subsection{Global Citizenship and Cosmopolitanism}

The literature on international development volunteering is replete with references to global citizenship, yet the term is rarely defined or explained by those using it. In fact, the term is frequently used in university settings, among civil society organizations, in development discourse, and in the public sector to characterize our moral obligations to the rest of humanity, a common identity, and way of living that recognizes and promotes international solidarity (Tiessen/Huish 2014; Cameron 2014). Unfortunately, as various scholars have noted, the term is often contested, elusive, vague, and associated with many contradictory definitions with almost no grounding in the political, philosophical, and ethical debates that might give the concept real meaning (Cameron 2014; Shultz 2007; Tiessen/Epprecht 2012). The range of possible meanings for global citizenship suggests that the term relies heavily on its conceptual vagueness (Lewin, 2009). In some definitions, individuals link their identity of global citizenship to notions of personal growth combined with other measures of societal change, while in others, global citizenship is defined as the ability to travel and live in other cultural contexts and to enhance intercultural relations (Heron/Tiessen 2012). It is important to note that how global citizenship is defined shapes the kind of experiences that volunteers have and encounter. For example, if global citizenship is framed and theorized as a method of 'helping' and 'saving' partners in the Global South, programming will inadvertently generate a narrative of global citizenship that reinforces neocolonial attitudes and neoliberal globalization (Rennick 2013).

For the purposes of this paper, I draw on the definition of 'global citizenship' from Heron and Tiessen (2007), who describe this as a way of understanding the world in which an individual's attitudes and behaviours reflect empathy for those marginalized and a concern for the relationship between poverty and wealth - within and between communities, countries, and regions..

The term global citizenship is part of a broader conception of global cosmopolitanism which denotes a new regionalism, or a strengthened global civil society supported by a new "normative architecture" of world order values (Tiessen/Epprecht 2012). Cosmopolitanism emphasizes the role of community on the global level as 
well as the formation of global norms. At the heart of cosmopolitanism is the conviction that by virtue of simply being human, all humans have certain moral obligations toward all other human beings (Cameron 2014). As an ideal, cosmopolitanism expresses the idea that all human beings - regardless of national, religious, cultural, or political affiliation - should be seen as members of the same community, and that this community should be cultivated. Likewise, cosmopolitan values put emphasis not just on positive moral obligations, but also on negative obligations to not cause harm, not benefit from harm, and to work to prevent harm (Cameron 2014). In other words, cosmopolitanism focuses on restructuring systems to reduce harm by putting heavy emphasis on the personal responsibility of all humans to be aware of the consequences of their actions on other humans.

It is important to note that many scholars (Cameron 2014; Dobson 2006; Linklater 2007) differentiate between 'thick' and 'thin' understandings of cosmopolitanism. Dobson (2006) argues that "thin conceptions of cosmopolitanism revolve around compassion for the vulnerable but leave asymmetries of power and wealth intact [whereas] thick conceptions of cosmopolitanism attempt to influence the structural conditions faced by vulnerable groups" (2006: 169). In essence, thick conceptions of cosmopolitanism call for informed and sustained political action aimed at ending the suffering of others in which we are implicated. On the other hand, thin conceptions of cosmopolitanism (e.g., international travel, volunteer work, and building skills) focus on the specific skills international volunteers (IVs) foster without situating those values and skills in the broader theoretical, ethical, and political context in which global justice is achieved. The next section will outline the role of International Development Volunteer (IDV) programs in promoting global citizenship and cosmopolitanism values.

\subsection{IDVs, Thick Global Citizenship, and Cosmopolitanism Values}

The scope for IDV programs to enhance global citizenship and cosmopolitan values in participants builds on the expectation that cross-cultural experiences with distant 'others' will lead to a greater openness to difference - a more cosmopolitan disposition (Vertovec/Cohen 2002). The narrative supporting this understanding is that IDVs are more likely to adopt a cosmopolitan outlook because they are more overtly exposed to cultures, values and places that they experience as foreign visà-vis their own cultural frames of reference (Rovisco 2009). This narrative, which focuses on the importance of building cosmopolitan identities through international volunteering, informs the rise of IDVs engaged in transnational interactions. However, many scholars question the expected impact of enhanced cosmopolitanism, noting that thin conceptions of global citizenship that may result often fail to grapple with the theoretical origins of the term. To motivate IDVs towards 'thicker' connections of cosmopolitan action, Linklater (2007) argues that volunteers must 
believe that they are causally responsible for harming others and their physical environment. Building off this argument, Dobson (2006) argues that "we are more likely to feel obliged to assist others in their plight if we are responsible for their situation - if there is some identifiable causal relationship between what we do, or what we have done, and how they are" (2006: 171). In other words, Dobson and Linklater both argue that it is in fact causal responsibility that fosters "thicker connections" between people and helps to shift beyond "the territory of beneficence and into the realm of justice" (Dobson 2006: 172). Moreover, thick conceptions of cosmopolitanism highlight the ways in which privileged citizens and consumers in the Global North are implicated in the global production of poverty and oppression (e.g., through unfair global trade rules and access to cheap material goods at the expense of communities in the Global South). This linkage and conceptualization of thick cosmopolitanism reinforces the debates around moral responsibilities and obligations.

The debate around IDVs developing cosmopolitan identities and values often focuses on the values experienced by the volunteers and rarely focuses on how intercultural experiences shape new cosmopolitan identities with the partner organizations receiving volunteers. This paper will focus on the latter by analyzing the changing cosmopolitanism identities of partner organizations in the Global South that engage with IDVs. I argue that IDVs play a pivotal role in transnational spaces and that cross-cultural encounters, reciprocal learning, and experiences of transnationalism need also to be examined from the perspective of those who 'receive' volunteers. These transnational encounters have specific implications for changing attitudes and cosmopolitan perspectives around gender equality and feminism and contribute to our understanding of trans-cultural relations for which culture is viewed as dynamic and fluid, and individuals carry different cultures that are not bound only to a nation-state or a region.

Gender equality has been a global priority for more than 40 years, since the adoption and ratification of the United Nations Convention on the Elimination of all forms of Discrimination against Women (CEDAW) in 1981. The 1995 Beijing conference and the resulting Beijing Platform for Action further laid out the priorities for a more equitable world that recognizes women's rights as human rights. Cosmopolitan priorities to advance gender equality can also be found in the Sustainable Development Goals (SDGs), specifically Goal 5 to Achieve Gender Equality and Empower all Women and Girls. These global priorities reflect the significance of a cosmopolitan vision for gender equality in the coming together of people from different countries to promote justice and equality for all. As a result of these global commitments, there has been an increase in IDVs working on gender-related projects, building capacity of gender-related themes, and working closely with local feminist organizations. 


\section{Methods}

Interviews were conducted in 2018 - 2019 with 150 partner organization staff in ten countries. Once all interviews were transcribed, data were coded to identify common themes throughout. The introduction to this special edition has more detailed information on the methodology for data collection and the analysis of findings.

\section{Findings}

Drawing on the interviews, this paper shines light on the changing cosmopolitan perspectives and global citizenship views of partner organizations that are developed as a result of with the transnational interactions with IDVs. Specifically, the research found that IDVs play a role in transnational spaces that further develop cosmopolitan values and that global citizenship values and understandings are enhanced through these transnational spaces through mutual learning and reciprocal knowledge sharing. The findings highlight five main themes: shifts in attitudes and behaviours towards gender equality; new insights and fresh ideas arising from interactions with IDVs; skills-building; the development of long-term relationships of reciprocity and mutual learning; and tensions between partner organizations and transnational interactions. Tensions are examined as they relate to the need for ongoing negotiation and mutual learning in these collaborative, transnational interactions.

One of the main findings that came out of this research was the role that cross-cultural exchange plays in building the capacity to shift attitudes and behaviours towards enhanced gender equality. Participants in this study often mentioned that dialogue with IDVs during workshops, casual conversations, and meeting reflections has given them the space to consider gender equality differently and to identify opportunities where gender equality can be mainstreamed into practice. The cross-cultural exchange was seen to have particular value in relation to advancing new insights and bringing in fresh ideas. One of the respondents in Tanzania mentioned the value of new ideas as a result of people coming from various environments and providing a new perception on gender equality, noting: "We need very fresh eyes on some old stuff so that we can modify or do them better. They say, if you are doing something for a very long time, you might develop monotony. Fresh eyes help us develop."

The Tanzanian participant went on to explain that these fresh insights are combined with locally-based understanding: "These experiences we are sharing from their country and our country, our perception of things, it develops both of us". The shared learning arises from each party having an opportunity to share their knowledge with each other: "[T]hey say what they have and [we say] what we have, we 
look at the gap and advocate to [fill it]. Through these interactions partner organization staff come to understand what is possible and what they can advocate for: "The results, we understand that we need to advocate more or to do more work so that we can achieve a sustainable gender equality, or gender equity which is present in their countries. Or we can have some sort of similarities but with regard to our culture also."

The contribution of fresh perspectives and ideas between IDVs and partner organizations around gender equality contributes to the breaking down of stereotypes or preconceived gender norms and towards enhancing cosmopolitan values among partner organizations. The diverse perspectives that IDVs contribute support partner organizations in identifying ways their practices and programs can mainstream gender equality. For example, in Ghana, one staff member of a partner organization noted the importance of IDVs who "insist we make sure they are gender sensitive such that it won't be all male or all female [in trainings]". This influence results in greater attention to all members of staff, their diverse roles and responsibilities and the need for better inclusion and equitable participation. While the focus here is on a gender-sensitive approach to programming focused on access and participation in training, our research found that IDVs were working towards building more nuanced understandings of gender equality, one that moved passed a liberal understanding.

Similarly, in Ghana the participating organization mentioned that IDVs bring new insights that encourage them to think about their practices differently. Building on the themes above, partner organizations refer to the influential role of IDVs who challenge partner organizations to ensure greater gender equality among their program beneficiaries. As the study participant from Ghana noted: "Gender equality has in a way improved since we started receiving the international volunteers in this organisation. They started pushing us that "why do we have only men holding higher position and women are not if they have the qualification?" The partner organizations used these opportunities to consider their program approach and to challenge themselves to advance gender equality in their programs by focussing on both male and female small-holder farmers. The participant concluded that the IDVs played a substantial role in helping the partner organization understand their work through a gender lens.

The capacity built through these relationships demonstrates the importance of relationship building and shared experiences through cross-cultural exchange. Specifically, the ways in which new perspectives and dialogue can help shift attitudes and breakdown stereotypes. Within the structural limitations of unequal systems and power structures, diverse experiences including opportunities, entry points, and development outcomes can be addressed in dialogue. 
One of the many roles IDVs play during their placement is to build capacity in their host organization across a spectrum of specializations and competencies. These skills include interpersonal skills; communication and technical writing; leadership training; gender equality training; computer literacy; and language training, among other skills. In this collection, Sadat provides a summary of the breadth of skills transferred and capacities built through IDV interactions. These skills and interactions with IDVs have supported partner organizations to reflect on their role in transnational spaces, their role in supporting gender equality, and also their role in enhancing global citizenship values. For example, in Peru, the participant organization mentioned that their interactions with IDVs encouraged them to reflect and discuss themes around controversial topics while also identifying ways to develop the capacity to learn how to communicate and address these difficult conversations with the community. The example of sensitive topics such as abortion was raised as one way that IDVs have created spaces to speak more openly about important topics. As the individual from Peru notes: "Here there was fear to speak on the theme of abortion, but we have conversed on how to approach this. We have reflected and developed capacities within ourselves.” The IDV, in this example, played an important role in helping the partner organization to translate their own feminist values and approaches into an understanding and conversation about abortion.

The findings highlight that the cross-cultural exchange with IDVs help partner organizations develop skills (both soft and hard skills) to integrate gender equality. Their exposure to the perspectives of IDVs has given partner organizations the opportunity to enhance their own skills and capacities and identify opportunities to integrate their learning to the local community. For example, an organization from Kenya stated that as a result of IDVs, the organization was able to develop gender sensitive policies around employment. Similarly, they were able to identify ways that they could use the internet to support the local women's market and increase their selling capacity. Of significance, however, is the way that skills - and capacity - building is viewed by the partner organizations in a cosmopolitan manner, not as an imposition from outside. The participants highlighted how the reciprocity of learning from each other's experiences created a transnational flow of gender equality because IDVs learned from the experiences of the partner organizations and vice versa. Further, in Kenya, one study participant (a member of a partner organization) spoke about the ways that cultural information is shared between partners and IDVs. They note that "people learn about our culture, and we learn about their culture, so there's no misconceptions or stereotypes." This interviewee noticed a change in their perspective from "interacting with [people from other communities around the world] and having time with them" it's totally changed my perspective." Moreover, the study participant goes on to suggest that every organization should benefit from these transnational encounters and sharing of knowledge, suggesting that many more people should "travel abroad and volunteer and 
get to learn about many different communities." Therefore, the learning and capacity building resulting from interactions with IDVs was not seen as one-directional. Rather, the findings from this research highlight the reciprocity and mutual learning of cosmopolitan values that happen in these transnational spaces.

The idea of mutual learning and knowledge sharing is understood as one that continues even after the IDV returns home. As one participant from Malawi noted, IDVs can continue to share their skills and what they have learned after they return home. The knowledge sharing also includes ways that Malawians have been able to "equip" IDVs with knowledge about Malawian cultural practices. The participant reinforced the significance of "exchange of experiences and innovative ideas." Beyond an emphasis on mutual learning is the significance accorded to the transnational flow of ideas that is multi-directional. The partner organization staff, as one study participant from Kenya notes, are "also giving them some skills also teaching them, you know it is kind of a two-way thing, they also learn."

The reciprocity and mutual learning that is created as a result of intercultural relations and interactions with IVDs has led to new cosmopolitan identities among partner organizations. Many partner organizations feel that the relationships they have built with IDVs have enhanced their cosmopolitanism and their views around gender equality. The key message shared by the participants in this research is that as an organization they are always in a learning environment, therefore anyone who enters that environment brings with them their skills and expertise but also leaves with skills and expertise from the organization. This reciprocity and mutual learning help formulate new identities both amongst the volunteers and amongst the partner organizations.

While this research has found that the cross-cultural exchange between IDVs and partner organizations supports the building of cosmopolitan identities among both stakeholders, the findings also demonstrate that there are limitations. IDVs can also reinforce cultural tensions in their efforts to promote gender equality where activities challenge gender norms or are perceived to challenge "tradition and culture". In Malawi, some partner organizations believed that IDVs were wasting their time trying to change the gender norms of the community because the communities would continue to see IDVs as "outsiders" and would not pay attention to calls for changing societal norms.

The emphasis being made by the partner organization in Malawi was that it is best for IDVs to focus their energy on training a number of community members and those community members working with the broader community on gender equality because they are insiders and know how to navigate the power dynamics that are embedded in community structures. Likewise, partner organization staff in several countries, including Ghana, Tanzania, and Malawi emphasized the 
importance of IDVs understanding the local context in which they are working to advance gender equality in order to ensure their work is sustained. As one organization in Malawi stated:

[...] when getting engaged in any country, first of all [you] should have a lot of knowledge about the culture of that particular country. If volunteers come without that knowledge, it will compromise our culture. They should know a lot [about] the country where they are going and understand the gap that is there on gender so that when they come, they are not there for a gender intervention [but], should be there as part of society to learn more, if then intervention should come on top of what you have already learnt [that's great]. Otherwise coming for the intervention, we want to change this and that, I don't think it can work.

This finding emphasizes that the perception of a lack of understanding IDVs have on the local culture and the resistance some community members may have toward initiatives try to advance gender equality. Further concerns were identified by partner organization staff in Ghana who highlighted the challenges arising from IDVs engaged in gender equality work when the programs leave men out. Shahadu Bitamsimli (this volume) addresses this in greater detail, noting that not all partner organization staff embrace outsider interventions on gender equality and women's empowerment, particularly when local men are not actively involved in finding solutions to gender problems. This finding reinforces the importance of understanding local culture, structures of power, key actors, and key spaces to navigate and advance gender equality. This was highlighted in a conversation with a partner organization in Peru that stated:

Firstly, and fundamentally, it is important to understand as much as possible and as quickly as possible, the history of Peru and to not make conclusions. As I said, it is one of the most violent countries against women, there is no justification for this, but there are ways to understand. And to transform things, you need to understand and not judge. In the history of 17 years working in social mobilization, with foreigners coming to Peru, they come down from the plane and try to explain why you live how you live... [IVs should] give more time to try to understand why we live in this chaos before giving answers.

This finding outline one of the key struggles and cultural tensions that exist between IDVs and partner organizations who work to address gender equality. Strategies to support gender equality cannot simply be imported and transmitted transnationally. This was reinforced by a partner organization in Ghana who stated that the IDVs' understanding of gender equality "is not possible to implement here [in Ghana] because we have our own culture and our own way of gender equality which is to create equal opportunities for women". These findings demonstrate the 
importance of transnational knowledge-sharing in ways that are respectful of local knowledge and cultural practices. While there was clear evidence among some of the study participants to the role of IDVs in the promotion of gender equality, the majority of the study participants highlighted opportunities for mutual learning and knowledge sharing so that the insights and ideas that IDVs bring could be incorporated into local knowledge and cultural realities.

Gender equality programming must be adapted and applied to the local context in ways that are informed and understood by the local community. This point reinforces the importance of mutual learning and reciprocity between IDVs and partner organizations as methods to reduce cultural tensions and increase new cosmopolitan identities.

\section{Analysis}

The findings highlight a shift in the dynamics that govern transnational spaces where IDVs and partner organizations interact. While much of the literature on IDVs focus on capacity building and the role of IDVs in bringing new forms of knowledge and expertise, the findings from this research emphasize the agency of partner organizations in creating reciprocity and mutual learning. In other words, the nature of the relationship between IDVs and partner organization is no longer framed or experienced as a unidirectional flow of ideas and experiences (Lough et al. 2009; Machin 2008). Rather, this research found that partner organizations view themselves as having the resources and the capacity to also give back to the volunteers. In fact, when it came to gender equality programming, partner organizations emphasized that IDVs required the knowledge of the organization to better understand the context and the approach to addressing gender equality. In other words, the shift in dynamic focused on IDVs working with partner organizations to enhance gender equality rather than replacing the work of partner organizations. This approach positioned partner organizations as active recipients engaging in a truly reciprocal exchange model, where neither actor is given exclusive benefit; give and take is expected from both sides (Hartman et al. 2014; Palacios 2010). In other words, the findings show that partner organizations in the Global South believe that mutual exchange and reciprocity actively exists among themselves and IDVs. This reciprocity as a mutual benefit was key in this research as it helped reduce the power differences that often exist in these transnational spaces. As Lough and Oppenheim (2017) argue, when reciprocity is low, volunteering as 'service' tends to reinforce power differences between giver and receiver - often in equal measure to other conventional aid relationships. However, in this research, the participant organizations acknowledged and argued for the importance of their role in these spaces and in their ability to effectively enhance gender equality both within their organization and in the communities where they work. 
The emphasis on mutual learning and reciprocity is supported by the assumption that "poor" people are best positioned to know how to articulate their problems, priorities, and the results of international projects (Narayan et al. 2000). This was clear in the numerous times participants in this research mentioned the need for local community members to discuss issues of gender equality rather than trainings run by IDVs, because as insiders the local community members know the tensions, problems, and priorities best. This finding further emphasizes the significance of the agency and voice of partner organizations. Specifically, highlighting the role partner organizations have played in transforming the spaces of intercultural exchange from one of imbalanced power - where IDVs would prescribe development outcomes and interpret the reality of local communities based on their own knowledge - towards one that reflects a more balanced exchange of knowledge, where Southern partner organizations are in the position to demand their voices be heard and to accurately interpret their own complex reality. As partner organizations have gained more experience working with IDVs and have built relationships with Northern partners, there is a shift in these transnational spaces where alternative voices are equally valued and legitimized, and where more authentic relations of reciprocity are able to form. Having the agency to choose how partner organizations like to advance gender equality, and how they best see the role of IDVs in their community, demonstrates that partner organizations are now in a position to carve out an understanding of how they wish to be represented rather than having their perspectives imposed upon them (Tiessen/Lough/Cheung 2018).

The shift in transnational space and the role of IDVs and partner organizations has been possible because of the rise of cosmopolitanism, a transnational mode of practice whereby actors construct bonds of mutual commitment and reciprocity across borders through public discourse and socio-political struggle (Cameron 2014). The relationships that partner organizations are making with IDVs in promoting a transnational flow of ideas on gender equality is in fact creating a 'cosmopolitanism from below'. This cosmopolitanism from below is premised on the multiplicity of experiences, the simultaneous existence of multilayered local, national, and global identities rather than to the notion of egalitarian universalism (Kurasawa 2004). As such, IDVs play a role in these transnational spaces to develop cosmopolitan values through relationship building, intercultural interactions, and listening to the voices of partner organizations. In this way, IDVs can support cosmopolitanism from below by learning and listening to the experiences of partner organizations in their efforts to advance gender equality, and forging links and networks with civic associations in both the Global North and the Global South to support these efforts. While the literature has focused on cosmopolitan values experienced by IDVs that privilege notions of global citizenship that seek to advance ideas of global solidarity through universalist conceptions, this research found that transnational interactions between IDVs and partner organizations are creating a new 
cosmopolitan from below that is characterized by identities that privilege bonds of mutuality and reciprocity between partners in different parts of the globe. This cosmopolitanism from below is advanced through the understanding that global solidarity can be derived from transnational webs of affinity that are themselves formed out of individuals and groups participating in processes of discussion and argumentation aiming to negotiate a common political terrain (Kurasawa 2004). As we saw in this research, partner organizations were seeking to advance gender equality on their own terms. While they required and appreciated the support of IDVs in identifying entry points and methods to approach gender equality, in the end, participants in this study found that it was insiders of the community that needed to do the negotiating, mobilizing, and advocacy to see change. This broader understanding of cosmopolitanism, a cosmopolitanism from below, informed by reciprocal learning, intercultural interactions, and transnationalism, is what is required in order to sustainably advance gender equality.

\section{Conclusion}

The findings analyzed in this paper consider the experiences of partner organizations in transnational spaces and the nature of reciprocity and mutual exchange in supporting gender equality programming. The research found that when it comes to gender equality programming, partner organizations have demonstrated their agency to advance feminist priorities while also advocating for the necessary components to achieve gender equality, and to be at the forefront of this change. This research found that partner organizations view themselves as having the resources and the capacity to advance gender equality programming - particularly when supported by IDVs - and that these transnational spaces should no longer be framed as spaces where there is a unidirectional flow of ideas and experiences.

Instead, this research found that transnational actors play a role in creating cosmopolitan identities in transnational spaces of mutual learning and reciprocity. In fact, transnational actors influence and benefit from transnational spaces to enhance their cosmopolitan views (impacts that are felt by IDVs and partner organizations alike). These transactions of knowledge and mutual learning are important for advancing gender equality and women's empowerment because it helps improve understandings of agency and structural realities. Specifically, it has helped partner communities both work within their own cultural communities as well as in transnational spaces with IDVs to facilitate changes towards social justice and support a 'cosmopolitanism from below'. This understanding provides nuance to understanding the relationship of IDVs with partner organizations as one that is multilayered with a multiplicity of experiences working towards an egalitarian universalism. In the efforts to advance gender equality, framing the relationship 
of IDVs and partner organizations as one that supports a 'cosmopolitanism from below' allows for an experience based on learning, listening, and empowering.

\section{Bibliography}

Cameron, John (2014): Grounding experiential learning in "thick" conceptions of global citizenship. In: Tiessen, Rebecca; Huish, Robert (ed.): Globetrotting or Global Citizenship? Perils and Potential of International Experiential Learning. Toronto, pp. 21-42.

Chapman, Deborah (2018): The ethics of international service learning as a pedagogical development practice: A Canadian study. In: Third World Quarterly, vol. 39, no. 10, pp. 1899-1922.

Dobson, Andrew (2006): Thick cosmopolitanism. In: Political Studies, vol. 54, pp. 165-184.

Hartman, Eric; Paris, Cody Morris; Blache-Cohen, Brandon (2014): Fair Trade Learning: Ethical standards for community-engaged international volunteer tourism. In: Tourism and Hospitality Research, vol. 14, no. 1-2, pp. 108-116.

Heron, Barbara; Tiessen, Rebecca (2007): Creating Global Citizens? The Impact of Learning/ Volunteer Abroad Programs. https://idl-bnc-idrc.dspacedirect.org/handle/10625/51024?show=full (3.10.2021).

Kurasawa, Fuyuki (2004): A Cosmopolitanism from below: Alternative globalization and the creation of a solidarity without bounds. In: European Journal of Sociology, vol. 45, no. 2, pp. 233-255.

Lewin, Ross (2009): The handbook of practice and research in study abroad: Higher education and the quest for global citizenship. New York.

Linklater, Andrew (2007): Distant suffering and cosmopolitan obligations. In: International Politics, vol. 44, no. 1, pp. 19-36.

Lough, Benjamin J.; McBridge, Amanda Moore; Sherraden, Margaret S. (2009): Perceived effects of international volunteering. https://www.brookings.edu/wp-content/ uploads/2016/06/0621_volunteering_mcbride.pdf (2.10.2021)

Lough, Benjamin. J.; Oppenheim, Willy (2017): Revisiting reciprocity in international volunteering. In: Progress in Development Studies, vol. 17, no. 3, pp. 197-213.

Machin, Joanna (2008): The impact of returned international volunteers on the UK: A scoping review. http://build-online.org.uk/documents/Impact\%20of\%20International\%20Volunteering\%20on\%20the\%20UK\%20VSO\%20Machin\%202008-1.pdf (3.10.2021).

Narayan, Deepa; Patel, Raj; Schafft, Kai; Rademacher, Anne; Koch-Schulte, Sarah (2000): Voices of the poor: Can anyone hear us? New York.

Palacios, Carlos (2010): Volunteer tourism, development and education in a postcolonial world: Conceiving global connections beyond aid. In: Journal of Sustainable Tourism, vol. 18 , pp. 861-878.

Rennick, Joanne (2013): Towards a pedagogy of good global citizenship. In: Rennick, Joanne Benham; Desjardins, Michel (ed.): The world is my classroom: International learning and Canadian higher education. Toronto, pp. 3-15.

Rovisco, Maria (2009): Religion and the challenges of cosmopolitanism: Young Portuguese volunteers in Africa. In: Nowicka, Magdalena; Rovisco, Maria (ed.): Cosmopolitanism in practice. Farnham, pp. 181-199. 
Shultz, Lynette (2007): Educating for global citizenship: Conflicting agendas and understandings. In: Alberta Journal of Educational Research, vol. 53, no. 3, pp. 248-258.

Tiessen, Rebecca; Epprecht, Marc (2012): Introduction: Global citizenship education for learning/volunteering abroad. In: Journal of Global Citizenship \& Equity Education, vol. 2, no. 1, pp. 1-10.

Tiessen, Rebecca; Lough, Bejamin J.; Cheung, Samuel (2018): Introduction: A theoretical and methodological case for examining agency and power relations in North-South volunteering research collaborations. In: Tiessen, Rebecca; Lough, Benjamin J.; Grantham, Kate (ed.): Insights on International Volunteering. Perspectives From the Global South. Germany, pp. 7-12.

Vertovec, Steven; Cohen, Robin (2002): Conceiving cosmopolitanism: theory, context and practice. Oxford. 